\title{
ESTIMATING THE PLANETARY BOUNDARY LAYER HEIGHT FROM RADIOSONDE AND DOPPLER LIDAR MEASUREMENTS IN THE CITY OF SÃO PAULO - BRAZIL
}

\author{
Márcia T. A. Marques ${ }^{1 *}$, Gregori de A. Moreira ${ }^{1}$, Maciel Pinero ${ }^{2}$, Amauri P. Oliveira ${ }^{2}$, Eduardo \\ Landulfo ${ }^{1}$ \\ ${ }^{1}$ CLA, IPEN/CNEN, Center for Lasers and Applications,Brazil,*marcia.marques@usp.br \\ ${ }^{2}$ University of São Paulo, IAG, Department of Atmospheric Sciences, Micrometeorology Group, Brazil
}

\begin{abstract}
This study aims to compare the planetary boundary layer height (PBLH) values estimated by radiosonde data through the bulk Richardson number (BRN) method and by Doppler lidar measurements through the Carrier to Noise Ratio (CNR) method, which corresponds to the maximum of the variance of CNR profile. The measurement campaign was carried during the summer of 2015/2016 in the city of São Paulo. Despite the conceptual difference between these methods, the results show great agreement between them.
\end{abstract}

\section{INTRODUCTION}

The planetary boundary layer (PBL) is the region of the atmosphere directly influenced by the Earth's surface, it is also defined by the exchange of heat, moisture and momentum with the surface. The PBLH is a fundamental parameter characterizing the structure of this region and is of great interest for meteorological applications, e.g., atmospheric modelling, air quality control and dispersion of pollutants [1], [2].

PBLH estimation relies on profile data analysis or its parametrization using equations and models [2]. In this study we will work with two different methods based on profile data. The most common measurements of profile data are taken by radiosondes that are widely used, although, standard radiosonde data are only taken twice a day, which doesn't allow a more detailed analysis.

Remote sense systems (lidars and sodars) are an alternative source of profile data that can provide continuous measurement of the PBLH with high spatial and temporal resolution, ideal for studying the PBL behavior. In this study we will work with a Doppler lidar system.
The PBL can be classified in a convective boundary layer (CBL), a well-mixed layer typically as a result of surface heating during the day and a stable boundary layer (SBL), a not well mixed layer where turbulence tends to be suppressed. The PBLH has different definitions in the $\mathrm{CBL}$ and in the SBL due to the PBL dynamics. The PBLH detection in the SBL presents much more difficulties due to features such as intermittent and weak turbulence and radiative cooling.

\section{METHODOLOGY}

The measurement campaign was carried during the summer of 2015/2016, from mid-December to early March, completing 80 days.

A commercial Doppler lidar model WLS70 from Leosphere was set up to measure vertical profiles of wind velocity, wind direction and CNR from 100 to $1500 \mathrm{~m}$ with vertical resolution of $50 \mathrm{~m}$ and recording 10 minutes averaging with a temporal resolution of $3 \mathrm{~Hz}$. The lidar was located at the top of the Center for Lasers and Application building at the University Campus in São Paulo (Figure 1), at $760 \mathrm{~m}$ above mean sea-level (233' $38^{\prime \prime}$ ' S, 46 44'25' W).

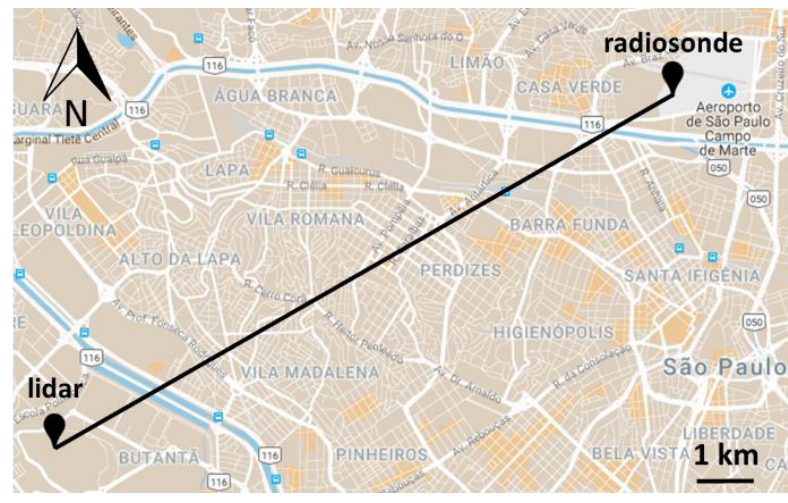

Figure 1 Study area scheme (Source: Google Maps) 
The radiosonde data used were launched from Campo de Marte airport (SBMT) located about 11 $\mathrm{km}$ northeast from the lidar measurement place (Figure 1), at $722 \mathrm{~m}$ above mean sea-level (2330'46' S, 46 38'30' W). The radiosonde was launched twice a day at 00 and 12 UTC. In this study we only used the 12 UTC data for the CBL, which corresponds to 09 PM local time. The radiosonde has a vertical resolution of tens of meters, but the available data are only of representative heights with a vertical resolution that can vary a few hundred meters.

The atmospheric conditions affected the lidar data availability, mainly because in São Paulo city the summer is the rainy season. The rain, some power outages and unavailable radiosonde data contributed to the reduction of available days for analysis, so of an 80-day dataset, only 49 days were chosen.

\subsection{CNR method}

The CNR method assumes that the PBLH is demarcated by a strong gradient of aerosol content where there is a transition between the PBL with high aerosol concentration and a relatively clean free atmosphere [3].

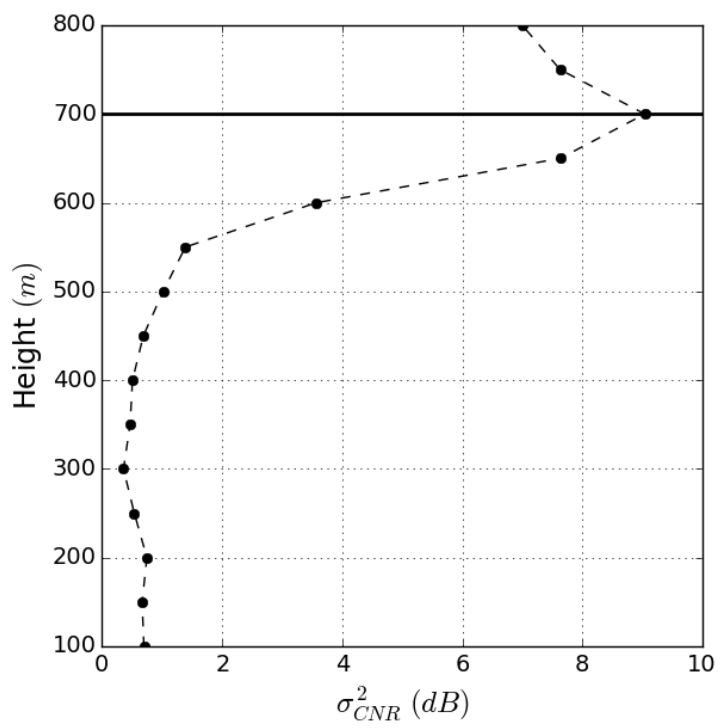

Figure 2 Example of the $\sigma_{C N R}^{2}$ vertical profile. The horizontal solid line indicates the PBLH

Therefore, the PBLH corresponds to the height at which the variance of the $\mathrm{CNR}\left(\sigma_{C N R}^{2}\right)$ is maximum as exemplified in figure 2 .

\subsection{BRN method}

The BRN is defined as the dimensionless ratio of buoyancy to shear production turbulence, expressed as:

$$
\operatorname{BRN}(z)=\frac{\left(g / \theta_{v s}\right)\left(\theta_{v z}-\theta_{v s}\right) z}{V_{h z}{ }^{2}}
$$

where $\theta_{v z}$ and $\theta_{v s}$ are the virtual potential temperatures at the height $\mathrm{z}$ and the surface, respectively, $g / \theta_{v s}$ is the buoyancy parameter, where $\mathrm{g}$ is the gravitational acceleration and $V_{h z}$ is the horizontal wind velocity at height $\mathrm{z}$.

The BRN method assumes that the PBLH corresponds to the height at which the BRN reaches a critical value that represents a transition between a turbulent and a laminar flow. In the literature we can find a variety of critical values, often between 0.21 and 0.25 . In this study we used a critical value of 0.17 estimated according to the methodology described by [4] based on linear fitting and statistical error minimization applied to different critical values. This methodology was applied to data from MCYTY BRAZIL program [5] that carried out 162 radiosondes launched every 3 hours collecting data with time resolution of $0.1 \mathrm{~Hz}$ at SMBT in 2013 .

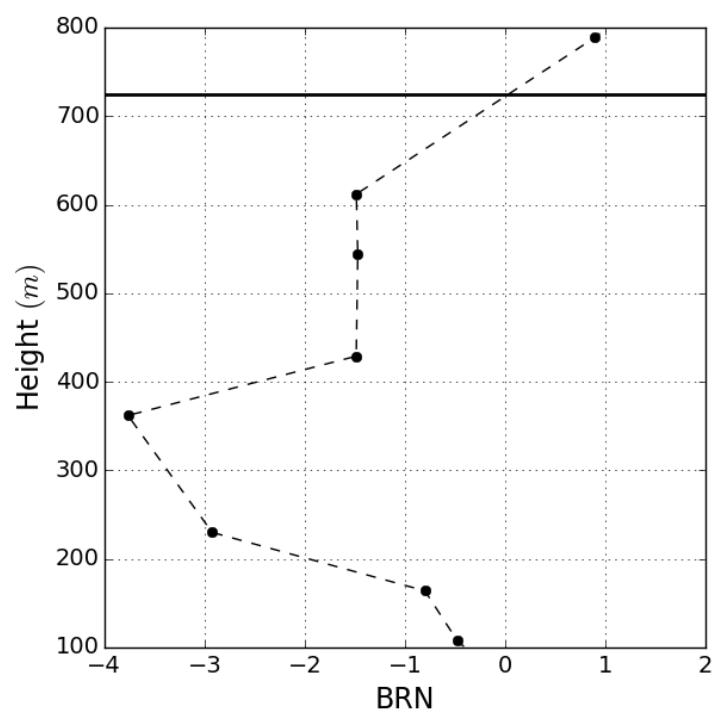

Figure 3 Example of the BRN vertical profile. The horizontal solid line indicates the PBLH

As previously mentioned, the vertical resolution of available radiosonde data is reduced, therefore, the PBLH was derived by a linear interpolation 
between the height where $\mathrm{BRN}<0.17$ and the height below [2].

\section{RESULTS}

PBLH was estimated by BRN and CNR methods for the chosen 49-day dataset at 12 UTC. Figure 4 shows the correlation between both methods with a Pearson correlation coefficient of 0.88 .

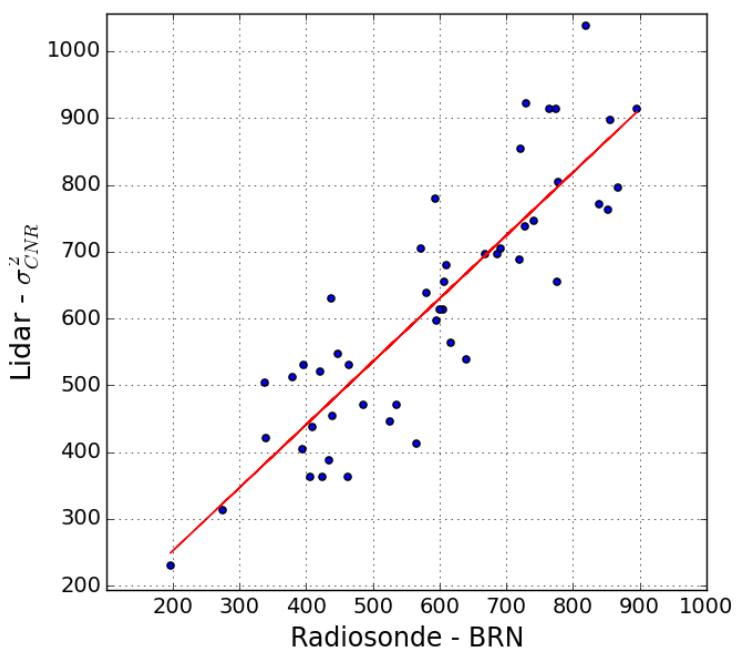

Figure 4 Correlation between PBLH estimated by both methods with a Pearson correlation coefficient of 0.88

Figure 5 shows the box plot of the estimated values for both methods. The center line of the box plot indicates the median value and the center box indicates the mean value.

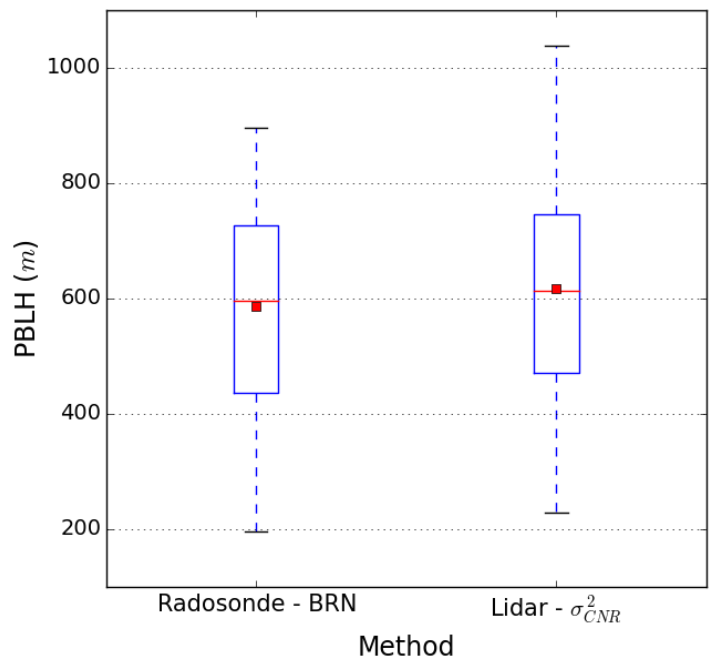

Figure 5 Box plot of PBLH estimated by both methods

The PBLH values estimated by CNR method were super estimated in comparison to the BRN method, as expected accordingly to [1]. The values were super estimated in $69 \%$ of the cases.

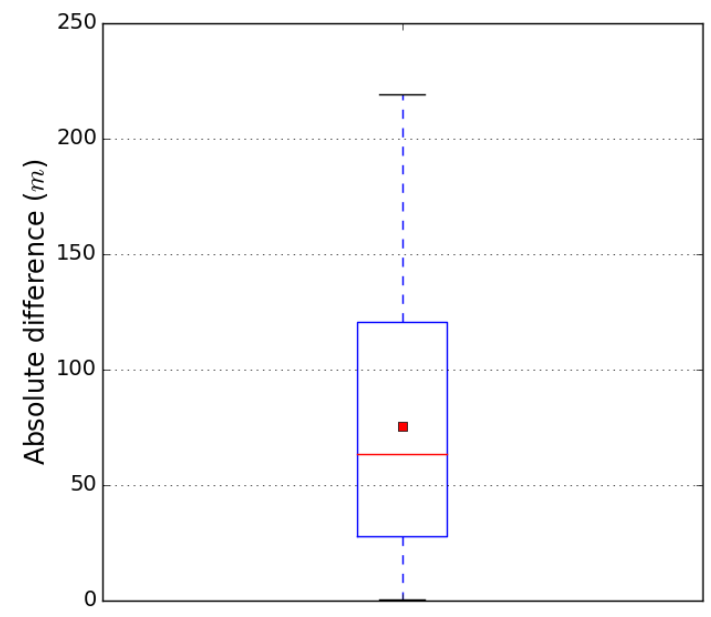

Figure 6 Box plot of the absolute difference between PBLH estimated by both methods

The average absolute difference is approximately $75 \mathrm{~m}$, which represents a relative difference of $12 \%$. Nevertheless, most absolute difference values are less than $75 \mathrm{~m}$ (Figure 6).

\section{CONCLUSIONS}

Considering these main limitations:

- Vertical resolution of 50 meters of the lidar (Figure 2) and a few hundred meters of the radiosonde (Figure 3) in which a linear interpolation between the levels of interest was carried out.

- Approximately $11 \mathrm{~km}$ distance between the measurements sites in a relatively complex terrain in the urban area.

- The conceptual definition of each method, which involves different definitions of the PBLH.

we were able to achieve a reasonable correlation between the methods (Figure 4). However, further investigation of PBLH behavior and the influence of other systems in the CBL can contribute to understand these differences

\section{ACKNOWLEDGEMENTS}

The author thankfully acknowledges the Micrometeorology Group from the Department of Atmospheric Science of the University of São 
Paulo for its contribution, the team of the Center for Lasers and Applications for the assistance in the measurement campaign and PETROBRAS Research Center for making the lidar available.

\section{References}

[1] Seibert, P., Beyrich, F., Gryning, S., Joffre, S., Rasmussen, A., Tercier, P., 2000: Review and intercomparison of operational methods for the determination of the mixing height, Atmos. Environ. 34 (7), 1001-1027.

[2] Zhang, Y., Gao, Z., Li, D., Li, Y., Zhang, N., Zhao, X., Chen, J., 2014: On the computation of planetary boundary-layer height using the bulk Richardson number method, Geosci. Model Dev. 7 (6), 2599-2611.

[3] Lothon, M., Lenschow, D. H.; Mayor, S. D., 2009: Doppler lidar measurements of vertical velocity spectra in the convective planetary boundary layer, Bound.-Layer Meteorol. 132 (2), 205-226.

[4] Sorensen, J. H., Rasmussen, A., Svensmark, H., 1996: Forecast of atmospheric boundary-layer height utilized for ETEX real-time dispersion modelling, Phys. Chem. Earth 21 (5-6), 435439.

[5] Oliveira, A. P., Marques Filho, E. P., Ferreira, M. J., Ribeiro, F. N. D., Soares, J., Codato, G., Mlakar, P., Boznar, M. Z., Pereira, M. M. R., Assis, E. S., Cassol, M., Escobedo, J. F., Dal Pai, A., França, J. R. A., Sánchez, M. P., Silveira, L. C., Buzati, B. C., Nofoente, J., Valdés, J., 2016: Assessing urban effects on the climate of metropolitan regions of Brazil Implementation and preliminary results of the MCITY BRAZIL PROGRAM for the cities of São Paulo and Rio de Janeiro, (submitted to Urban Climate). 